\title{
An Exceptionally Stable and Widespread Hydrated Amorphous Calcium Carbonate Precipitated By the Dog Vomit Slime Mold Fuligo Septica (Myxogastria)
}

\section{Laurence A.J. Garvie ( $\square$ lgarvie@asu.edu )}

Arizona State University

\section{Péter Németh}

Eötvös Loránd Research Network

\section{László Trif}

Institute of Materials and Environmental Chemistry, Research Center for Natural Sciences

\section{Research Article}

Keywords: amorphous calcium, ACC, XRD, TEM

Posted Date: November 30th, 2021

DOI: https://doi.org/10.21203/rs.3.rs-1097298/v1

License: (1) (1) This work is licensed under a Creative Commons Attribution 4.0 International License.

Read Full License

Version of Record: A version of this preprint was published at Scientific Reports on March 7th, 2022. See the published version at https://doi.org/10.1038/s41598-022-07648-9. 


\section{Abstract}

Biogenic amorphous calcium carbonate (ACC) is typically metastable and can rapidly transform through aging, dehydration, and/or heating to crystalline calcium carbonate. Gaining insight into its structure and properties is typically hampered by its tendency to crystallize over short time periods once isolated from the host organism, and also by the small quantities that are usually available for study. Here, we describe an exceptionally stable hydrated ACC (HACC) precipitated by the cosmopolitan slime mold, Fuligo septica (L.) F.H. Wigg. (1780). A single slime mold can precipitate up to one gram of HACC over the course of one night. Powder x-ray diffraction (XRD) patterns, transmission electron microscopy (TEM) images, infrared absorption (IR) spectra, and lack of optical birefringence are consistent with an amorphous material. XRD simulations supported by thermogravimetric (TG) and evolved gas analysis (EGA) data suggest an intimate association of organic matter with 1-nm-sized ACC units that have monohydrocalcite- and calcite-like nano-structural properties. It is postulated that this association imparts the extreme stability of the HACC by preventing loss of $\mathrm{H}_{2} \mathrm{O}$ and subsequent crystallization. The composition, structure, and thermal behavior of the HACC precipitated by F. septica collected over $8000 \mathrm{~km}$ apart, and in markedly different environments, suggests a common structure, as well as similar biochemical and biomineralization mechanisms for the HACC formation.

\section{Introduction}

Considerable work is ongoing with the view of understanding the structure of amorphous calcium carbonate (ACC), and the mechanisms by which it crystallizes ${ }^{1-9}$. ACC is typically a transient material that transforms into crystalline calcium carbonate. For example, laboratory synthesized ACC can transform within minutes to vaterite and calcite ${ }^{10}$, and synthetic ACC free of stabilizing ions or organic molecules typically forms crystalline to $\mathrm{CaCO}_{3}$ within a few days ${ }^{11,12}$. Biogenic $\mathrm{ACC}$ can be broadly divided into transient anhydrous ACC and comparatively more stable material with $\sim 1$ mol of water ${ }^{13-15}$. Biogenic and synthetic hydrated ACC typically contains about $1 \mathrm{~mol} \mathrm{H}_{2} \mathrm{O}$. For example, synthetic ACC can contain between 1.13 to 1.58 moles of $\mathrm{H}_{2} \mathrm{O}{ }^{5,7,16}$, with mass losses up to $200^{\circ} \mathrm{C}$ similar to that measured for monohydrocalcite. Though, $\mathrm{ACC}$ has been synthesized with lower $\mathrm{H}_{2} \mathrm{O}$ contents, e.g. 5,17. Characterization of ACC is challenging as it can be difficult to detect, in part because of its instability, and its presence may be masked by crystalline Ca carbonates.

ACC can be stabilized, or is metastable, in the presence of inorganic ions, including $\mathrm{Mg}^{2+}$ and phosphate, and organic molecules ${ }^{13,14,18-20}$. For example, ACC produced by cave bacteria is stable in the presence of extracellular polysaccharides ${ }^{19}$. While the bacteria produce a wide range of organic molecules at their cell wall surface, the presence of large amounts of long-chain fatty acids suggests that the ACC could be enclosed in micellar-like units that inhibit water infiltration, and thus stabilize the ACC. Earthworms ACC can remain stable for years ${ }^{21}$. Its ACC contains high concentrations of amino acids, suggesting a stabilizing role of the organic compounds. Similarly, ACC from an ascidian skeleton contains 
glycoproteins, with high concentrations of glutamic acid and hydroxy amino acids: these macromolecules are suggested to play a role in the stability of the ACC ${ }^{14}$.

Structural investigations of ACC suggest a range of short-range orderings, from vaterite-like ${ }^{1}$, calcite-like 1,3 and monohydrocalcite-like structures ${ }^{4}$, though others suggest that the short-range order is inconsistent with known calcium carbonate structures ${ }^{5}$. Despite these diverse viewpoints, the structural analyses for ACC universally suggest short-range order. For example, Ca EXAFS data is consistent with a structure lacking coherence above $1.5 \mathrm{~nm}^{5}$, suggesting that short-range order does not extend beyond the first coordination shell of $\mathrm{Ca}$, which is about $0.4 \mathrm{~nm}$ from the central $\mathrm{Ca}$ atom ${ }^{4}$. Further, Sun et al. ${ }^{9}$ synthesized organic protected clusters of $\mathrm{ACC}$ with seven $\mathrm{CaCO}_{3}$ units with an $\sim 1.4 \mathrm{~nm}$ core. The ${ }^{13} \mathrm{C}$ NMR and Ca K-edge EXAFS data demonstrate the rather disordered nature of the Ca sites with a mixture of $\mathrm{Ca}-\mathrm{O}$ coordinations, geometries, and bond lengths. However, despite this disorder, the data suggest a proto-calcite-like short-range order. In contrast, Rez et al. ${ }^{8}$ proposed a nanocrystallite model for ACC consisting of randomly oriented 1-nm-sized nanocrystals with water molecules between the distorted nanocrystallites. This model is based on the idea of coherent x-ray diffraction from randomly oriented $\sim 1$ $\mathrm{nm}$-sized crystallites, which gives rise to a diffraction profile that is characterized as amorphous. Goodwin et al. ${ }^{2}$ developed a model for synthetic ACC consisting of a porous Ca-rich framework that supports interconnected channels containing water and carbonate molecules, though still lacking longrange order. These data, and those from other studies imply that not all ACC is the same ${ }^{22}$, i.e., there is unlikely a universal ACC structure.

A wide range of organisms precipitate ACC, including worms, mollusks, sponges, crustaceans, ascidia, bacteria, myxogastria, avian eggshells, and plants, ${ }^{14,19,21,23-26}$. Particularly widespread, though less frequently studied, is the structure of the calcium carbonate precipitated by the myxogastria, a group of organisms commonly called slime molds ${ }^{27-31}$. Study of slime mold carbonate is typically hampered by the small sizes of most species. However, some form $\mathrm{cm}$ - to dm-sized spore-filled masses called aethalia, which can be covered by a mineralized coating called a peridium ${ }^{32}$. Most notable are the aethalia produced by the cosmopolitan species Fuligo septica ${ }^{32,33}$, which can be up to $75 \mathrm{~cm}$ across ${ }^{33}$. The calcium carbonate precipitated by slime molds typically occurs as micron and submicron-sized spheres or euhedral crystals $27,28,31,32,34-36$, though rarely is the precipitated material characterized, and is variously referred to as "lime", in the literature. For example, Schoknecht ${ }^{30}$ employed a scanning electron microscope with $\mathrm{x}$-ray microanalysis to study the calcareous deposits from a range of acellular slime molds: the presence of crystalline versus amorphous $\mathrm{CaCO}_{3}$ was based on crystal shapes. There is evidence to suggest that the calcium carbonate precipitated by $F$. septica peridium is in part amorphous 28.

In this study, we describe and characterize the ACC formed by the cosmopolitan slime mold F. septica (L.) F.H. Wigg (1780) ${ }^{37}$, commonly known as the dog vomit or scrambled-egg slime mold. The structure, characteristics, and composition of the freshly precipitated peridium is revealed using powder $\mathrm{x}$-ray 
diffraction (XRD), scanning and transmission electron microscopy (SEM and TEM), infrared spectroscopy (IR), thermal techniques (TG - thermogravimetric analysis, DSC - differential scanning calorimetry, and MS-EGA - mass spectroscopic evolved gas analysis), and bulk elemental analysis by proton-induced x-ray emission (PIXE) and $\mathrm{CHN}$ analysis. These techniques were also used to follow the laboratory dehydration of the as-precipitated, hydrous ACC (HACC) to a dehydrated form (DACC), and the crystallization to calcite. The sequence of transformations is HACC to DACC, which is stable to $322^{\circ} \mathrm{C}$, crystallization of calcite between 322 and $440^{\circ} \mathrm{C}$, and complete transformation to calcite by $450^{\circ} \mathrm{C}$. A major finding of our study is that the F. septica HACC and DACC are indefinitely stable under normal laboratory conditions. Our data are consistent with an intimate association of organic matter with $\sim 1$-nm-sized ACC units that have monohydrocalcite- and calcite-like nano-structural properties. It is speculated that this association imparts the extreme stability of HACC by preventing loss of $\mathrm{H}_{2} \mathrm{O}$ with subsequent crystallization.

\section{Results And Discussion}

Characterization of the field collected ACC. Aethalia from 37 F. septica specimens were collected (See Field Observations under Methods) and stored under normal laboratory conditions. The aethalia consists of an inner spore mass and an outer peridium. The peridium is the thin, to 3-mm thick, brittle porous coating that covers and surrounds the spore-bearing aethalium (Figs. 1a, b, S1c). The specimens from southern Arizona are white (referred to as FSW for Fuligo Septica White) and the UK specimens are bright lemon yellow (referred to as FSY) (Figs. 1, S1, S2). The yellow of the FSY specimens is caused by a range of pigmented compounds including the tetramic acid derivative fuligorubin $A^{38}$, which also acts as a metal chelating agent 39,40 . Observations of the Arizona specimens by the senior author showed formation of the aethalium during the evening and early hours of the morning within a few days following summer rains. By morning, the aethalia are fully developed and samples were collected for study. Fragments of the peridia free of the spores were separated for analysis (Fig. S2).

A combination of PIXE, TG analysis, and CHN analysis were used to analyze the elemental composition of the FSY and FSW peridia (Tables 1, S1, S2). Calcium is the major cation. The FSY samples contain 3.3 wt\% Mn, whereas the FSW samples contain between 937 and 2186 ppm Mn. Magnesium was typically at or below the PIXE detection limit of $\sim 200 \mathrm{ppm}$ : the only other elements consistently above the limit of detection for the PIXE are P, S, Cl, and K (Table S1).

Optical, SEM, and TEM images show the peridia composed of 500- to 1500-nm-sized spheres (Figs. 1, 2, S1d), consistent with previous SEM images ${ }^{28}$. The spheres are isotropic under crossed polarized transmitted light (Fig. 1f). The high-angle annular dark-field scanning TEM (HAADF-STEM) and brightfield TEM (BFTEM) images show that the spheres typically have an internally mottled appearance. This mottling is especially evident in the BFTEM images, which show rounded, 20- to 40-nm-sized electron dense units (Figs. 2c and S3). The selected-area electron diffraction (SAED) patterns of the spheres show diffuse rings (Fig. 2d), similar to what was reported by Enyedi et al. ${ }^{19}$ for bacterially precipitated ACC. 
Multiple peridial samples were examined by powder XRD: all lack the sharp intense Bragg reflections of crystalline phases, and are instead dominated by five broad, but well-defined maxima at 1.9, 0.46, $0.2866,0.204 \mathrm{~nm}, 0.119 \mathrm{~nm}$, and weak maxima at higher d-spacings (Fig. 3). The high signal-to-noise ratio of our powder XRD patterns, compared with published data, was possible because of the large amount of pure HACC produced by the slime mold, and its exceptional stability in air. For example, the XRD patterns of the FSW and FSY samples acquired within hours of formation compared with those stored in the laboratory for two years are identical. Except for the $\sim 1.9 \mathrm{~nm}$ reflection, the diffraction patterns are similar to those for synthetic and biogenic ACC $5,7,26,41-43$. The prominent $\sim 1.9 \mathrm{~nm}$ has not previously been reported and suggests ordering at the $\sim 2 \mathrm{~nm}$ scale.

The FTIR spectra of the HACC (Figs. 4, S4, S5) show the characteristic bands of ACC, with spectra similar in shape to biogenic (e.g., Fig. 2a and b, and in Addadi et al. ${ }^{23}$ ) and synthetic ACC (Radha et al. ${ }^{7}$ supplement). The FSY and FSW HACC spectra lack the distinctive $\mathrm{v}_{4}$ band for crystalline $\mathrm{CaCO}_{3}$, i.e., 712 $\mathrm{cm}^{-1}$ for calcite and $744 \mathrm{~cm}^{-1}$ for vaterite. Instead, the HACC spectra display low-intensity bands at 727 and $693 \mathrm{~cm}^{-1}$ that sit on a broad band centered near $600 \mathrm{~cm}^{-1}$. The IR spectrum shows the broad band between $2750-3800 \mathrm{~cm}^{-1}$ from absorbed and structural water, on which are superimposed weak absorption bands for organic material (inset Fig. S4). In comparison to the amorphous HACC, aged samples collected in the desert show FTIR spectra with characteristic absorption bands for crystalline $\mathrm{CaCO}_{3}$ (Figs. S4, S5).

The moisture stability of the FSY and FSW samples was investigated by placing the XRD slide with the sample used for powder XRD into a sealed container over water at $50^{\circ} \mathrm{C}$ for $24 \mathrm{hrs}$. The sample became damp over the $100 \% \mathrm{RH}$ and a new powder XRD pattern was acquired. The FSY ACC diffraction pattern was unchanged, even after several $24 \mathrm{hr}$ sessions of the $100 \% \mathrm{RH}$ treatment. However, the FSW ACC showed the appearance of calcite reflections after one $24 \mathrm{hr}$ session of $100 \% \mathrm{RH}$. These reflections became more intense with each $24 \mathrm{hr}$ sessions of $100 \% \mathrm{RH}$, though no reflections for vaterite were noted (Fig. S6). In contrast, FSW samples collected after weeks to months of natural desert weathering are dominated by vaterite with minor calcite, to those dominated by calcite with minor vaterite: one peridium is composed of monohydrocalcite with minor amounts of calcite (Fig. S7).

Thermal response. The TG curves for the ACC samples studied under a He atmosphere show four distinct mass-loss steps, M1 to M4 (Figs. 5, S8, S9). The total mass losses for the FSW and FSY samples heated to $1000^{\circ} \mathrm{C}$ were typically between 52 and $57 \%$. The DSC curves show an endothermic peak at $\sim 100^{\circ} \mathrm{C}$, corresponding to dehydration of the HACC and loss of loosely bound water (Fig. 5). The TG loss below $200^{\circ} \mathrm{C}$ is between 10.5 and $10.9 \%$ for the FSW samples (samples FSW21 and FSW18) and $11.2 \%$ for FSY. The EGA ion curves show that the mass loss below $200^{\circ} \mathrm{C}$ is dominated by the evolution of $\mathrm{H}_{2} \mathrm{O}$ with minor $\mathrm{CO}_{2}$ (Fig. 5, S10, S11). In region M2, the mass loss is dominated by $\mathrm{H}_{2} \mathrm{O}\left(3.8 \%\right.$ ), $\mathrm{CO}_{2}$ (Fig. S11) and organic molecules (Fig. S10d): the intense $\mathrm{m} / \mathrm{z}=30$ signal matches that of formaldehyde (see caption to Fig. S10 for additional ion peak assignments). During the M3 mass-loss step (between 396 and $584^{\circ} \mathrm{C}$ ), organic matter is pyrolytically degraded (Fig. S12), with the evolution of a range of organic-bearing 
species, with minor $\mathrm{H}_{2} \mathrm{O}$ and $\mathrm{CO}_{2}$ (Fig. S10). Above $584^{\circ} \mathrm{C}$, calcium carbonate decomposes, and the ion signals are dominated by $\mathrm{m} / \mathrm{z}=44$ corresponding to $\mathrm{CO}_{2}$ (Figs. $5, \mathrm{~S} 10$ ).

Quantity of water and organic matter. The FSY and FSW HACC shows TG mass losses up to $200^{\circ} \mathrm{C}$ of $\sim 11 \mathrm{wt} \%$, the majority of which is $\mathrm{H}_{2} \mathrm{O}$. For example, of the $11.2 \%$ mass loss for FSY below $200^{\circ} \mathrm{C}$ (Fig. $\mathrm{S} 11$ ), $10.9 \pm 0.1 \%$ is from $\mathrm{H}_{2} \mathrm{O}$, and the rest is $\mathrm{CO}_{2}$ (see Supplementary section - Water Calculation from TGDSC-MSEGA measurements). A further $3.8 \% \mathrm{H}_{2} \mathrm{O}$ is released in region $\mathrm{M} 2$ (Fig. S11), though only $3.0 \%$ up to the crystallization temperature onset at $322^{\circ} \mathrm{C}$ (see discussion below). However, considering the composition of the FSY HACC as inorganic Ca-C-O-O-O-H-H-O (equivalent to monohydrocalcite: $\mathrm{CaCO}_{3} \cdot \mathrm{H}_{2} \mathrm{O}$ ) + remaining $\mathrm{C}-\mathrm{H}-\mathrm{N}-\mathrm{O}$, then $13.72 \mathrm{wt} \%$ water loss (corresponding to 1 mole of water) is expected (Tables S3, S4). The lower-than-expected amount of water released below $200^{\circ} \mathrm{C}$ for FSY, i.e., $1 \mathrm{CaCO}_{3}: \mathrm{nH}_{2} \mathrm{O}$ ratio with $\mathrm{n}<1$, may indicate significant molecular $\mathrm{H}_{2} \mathrm{O}$ retained above $200^{\circ} \mathrm{C}$, but released before and during crystallization of the ACC starting near $322^{\circ} \mathrm{C}$. Such a scenario is borne out by the TG data which shows a total $\mathrm{H}_{2} \mathrm{O}$ release up to $322^{\circ} \mathrm{C}$ of $13.9 \%$. While the low-temperature water-loss peak has a maximum just above $100^{\circ} \mathrm{C}$, which then drops precipitously with a plateau near $200^{\circ} \mathrm{C}, \mathrm{H}_{2} \mathrm{O}$ continues to be released with increasing temperature and peaks near $320^{\circ} \mathrm{C}$, with little $\mathrm{H}_{2} \mathrm{O}$ detected above $400^{\circ} \mathrm{C}$ (Figs. S10a, S11). These data suggest that the water released between 200 and $320^{\circ} \mathrm{C}$ has several sources including molecular $\mathrm{H}_{2} \mathrm{O}$ and that bound to the organic compounds.

The FTIR spectra show weak absorption bands between 2800 and $3000 \mathrm{~cm}^{-1}$ attributed to organic matter associated with the HACC (Fig. S4). The breakdown of this organic matter is also detected by EGA during heating of the HACC (Fig. S10). Samples heated in air have a higher mass loss than those heated under an inert atmosphere (Fig. S13). For example, FSY shows higher mass losses when heated in air between 200 and $575^{\circ} \mathrm{C}$. In this temperature range, $19 \%$ of the mass is lost in the case of samples measured in air, and $15.1 \%$ when heated under He. This 4\% difference sets a minimum in the FSY sample on the organic content as some is pyrolytically degraded under He. The quantity of organic matter can also be estimated from the compositional data (Tables 1, S3 to S6). Assuming an inorganic formula for FSY as $(\mathrm{Ca}, \mathrm{Mn})_{1} \mathrm{CO}_{3} \cdot \mathrm{H}_{2} \mathrm{O}$, then the remainder is assumed to be organic and has the composition $\mathrm{C}_{0.60} \mathrm{O}_{0.09} \mathrm{H}_{1.41} \mathrm{~N}_{0.14}$, which is $9.13 \%$ of the original HACC mass (Tables S3, S4). Similarly, the composition for FSW21 (Table 1) suggests it contains $9.83 \%$ organic matter (Tables S5, S6). Thus, the TG data is consistent with the F. septica HACC containing between approximately 4 and $10 \%$ organic matter.

Despite the elemental and compositional similarities between the F. septica HACC and monohydrocalcite (Table 1), their thermal behaviors differ significantly. Monohydrocalcite typically dehydrates by $226^{\circ} \mathrm{C}$, with mass loss of $15.25 \% \mathrm{H}_{2} \mathrm{O}$, corresponding to $\mathrm{CaCO}_{3} \cdot \mathrm{H}_{2} \mathrm{O} \rightarrow \mathrm{CaCO}_{3}+\mathrm{H}_{2} \mathrm{O}$, and 37.26 wt\% mass loss above $530^{\circ} \mathrm{C}$ for $\mathrm{CaCO}_{3} \rightarrow \mathrm{CaO}+\mathrm{CO}_{2} 44,45$. Monohydrocalcite shows minimal mass loss below $\sim 180^{\circ} \mathrm{C}$, and between $\sim 200$ and $500^{\circ} \mathrm{C}$. In contrast, the slime mold ACC shows significant mass loss below $180^{\circ} \mathrm{C}$, and also between 200 and $500^{\circ} \mathrm{C}$. The slime mold thermal data are consistent with the different $\mathrm{H}$ environments, similar to that detected in ACC by Nuclear Magnetic Resonance spectroscopy ${ }^{16}$, viz., fluid- 
like $\mathrm{H}_{2} \mathrm{O}$, rigid structural $\mathrm{H}_{2} \mathrm{O}$, restrictedly mobile $\mathrm{H}_{2} \mathrm{O}$, and hydroxyl. Our mass loss up to $200^{\circ} \mathrm{C}$ is dominated by the loss of fluid-like $\mathrm{H}_{2} \mathrm{O}$.

Laboratory crystallization of the DACC. The powder XRD data show onset of crystallization of the DACC between 300 and $350^{\circ} \mathrm{C}$ (Fig. S14). Similarly, SAED patterns and FTIR spectra of the HACC heated at $208^{\circ} \mathrm{C}$ show an amorphous material, but at $362^{\circ} \mathrm{C}$ the patterns and spectra show partial crystallization, and at $500^{\circ} \mathrm{C}$ the spheres are calcite (Fig. S15 to S17). At $362^{\circ} \mathrm{C}$, the BFTEM images show that the newly formed calcite is $\sim 40 \mathrm{~nm}$, which is similar in size to the electron-dense aggregates imaged by BFTEM in the nanospheres (Fig. 2C, S3). By $500^{\circ} \mathrm{C}$, the $40-\mathrm{nm}$ nano-objects have organized into micron-sized grains and form calcite (Fig. S15). The spherical morphology is preserved during the transition (Fig. S15). Individual spheres show sharp extinction when rotated between the crossed polars, indicating that each is a single crystal and preserves the original spherical morphology.

The DSC profiles for HACC samples examined under He show peaks for exothermic reactions between 300 and $480^{\circ} \mathrm{C}$ (Fig. 5). The FSY sample shows prominent maxima at 327 and $401^{\circ} \mathrm{C}$ in the raw thermogram. Most of the FSW samples similarly reveal two well-resolved exothermic maxima near 338 and $414^{\circ} \mathrm{C}$ (Fig. S18). One sample (FSW21) lacks the $338^{\circ} \mathrm{C}$ maximum. The EGA data show a maximum in the evolution of a range of gases just prior to the first exotherm maximum for both the FSY (Fig. 6) and FSW (Fig. S19) precipitated HACC. Many of the gases associated with organic molecules show a twopeaked evolution with maxima at $\sim 260$ and $\sim 320^{\circ} \mathrm{C}$, whereas water and $\mathrm{CO}_{2}$ show a more gradual increase in signal intensity starting around $240^{\circ} \mathrm{C}$, with a maximum near $320^{\circ} \mathrm{C}$. The first exotherm between 327 and $338^{\circ} \mathrm{C}$ is within the crystallization range identified by powder $\mathrm{XRD}$, and previously attributed to the crystallization of the dehydrated $A C C$ 7,17,41,46, although this maximum can occur over a range of temperatures ${ }^{16}$. Some biogenic ACCs show two exothermic peaks in the 330 to $370^{\circ} \mathrm{C}$ range ${ }^{47}$. For example, the "Gastrolith ACC 2" DSC curve from ${ }^{47}$ shows two exothermic peaks, of which one may be attributed to the breakdown of chitin ${ }^{48}$. Between the first and second exotherm, the slime mold ACC continues to lose mass, typically between 1.3 and $3.5 \mathrm{wt} \%$. However, additive free ACC does not typically show mass loss following the exothermic event near $340^{\circ} \mathrm{C}$, indicating a solid-state transformation to calcite as no remaining water is available 7,17 .

Our data suggests the breakdown of an organic framework to the DACC starting near $240^{\circ} \mathrm{C}$, culminating with a maximum in several EGA signals just prior to the first DSC exotherm, with partial crystallization. The powder $X R D$ data for the sample at $350^{\circ} \mathrm{C}$ still shows a significant amorphous contribution (Fig. $\mathrm{S} 14)$. By $365^{\circ} \mathrm{C}$, the powder XRD pattern shows intense reflections for calcite that sit on a less intense amorphous ACC background. Optical microscopy shows that at $365^{\circ} \mathrm{C}$, approximately $20 \%$ of the spheres are isotropic. The DSC maximum near $400^{\circ} \mathrm{C}$ likely corresponds to the onset of crystallization of the remainder of the as yet amorphous part of the ACC, as optical microscopy and powder XRD of samples heated at $446^{\circ} \mathrm{C}$ show calcite only.

Multi-scale structure of the HACC. Our data for the F. septica HACC is consistent with the following structural spatial scales, viz., 1) the 500- to 1500 -nm-sized sphere; 2 ) tens-of-nanometer-sized clumping 
within the spheres; 3) an 2-nm-scale ordering as revealed by the powder XRD; and, 4) the short-range ordering that gives rise to the bulk powder XRD pattern. Some of the structural characteristics of the HACC may be explained by the formation mechanisms of the individual spheres. Electron microscopy shows the aggregation and excretion of calcium during sporogenesis in the slime mold Physarella oblonga ${ }^{27}$, which is in the same family as F. septica, the Physaraceae ${ }^{49}$. As the slime mold transforms from the mobile plasmodium to the sessile fruiting body there is a massive elimination of the protoplasmic $\mathrm{Ca}$. During sporogenesis, electron microscopy reveals the formation and aggregation of tens-of-nanometers-sized Ca-rich, electron-dense, membrane-bound intracellular grains. These grains aggregate and assume their final spherical shape as they grow and are expelled and form the peridium 27. This membrane-bound aggregate model is consistent with our BFTEM of the $F$. septica spheres, which internally show tens-of-nanometer-scale electron-dense clumping (Figs. 2c, S3). However, the aggregates themselves are amorphous as the powder XRD profiles do not show reflections indicative of crystalline ordering at the tens-of-nanometer scale (Fig. S21).

The origin of the $\sim 1.9 \mathrm{~nm}$ powder XRD maximum is obscure. This maximum becomes indistinct, or is absent, for samples heated to $\sim 100^{\circ} \mathrm{C}$, or stored over the aggressive drying agent $\mathrm{P}_{2} \mathrm{O}_{5}$. Thus, the $1.9 \mathrm{~nm}$ maximum may reflect ordering at this scale that is absent after loss of the weakly bound water. Ordered mesoporous material can give rise to low-angle maxima that reflect the pore-to-pore distance as well as the pore diameter ${ }^{50}$. Thus, the $\sim 1.9 \mathrm{~nm}$ maximum suggests an ordered mesoporous structure to the $F$. septica HACC that is readily lost on removal of the loosely bound water.

The powder XRD patterns for the room temperature and heated $F$. septica ACC lack discrete reflections for crystalline phases, and instead present broad maxima that reflects the short-range order within the spheres. These maxima represent the average interatomic distance scattering within the material and are indicative of short-range order. Rez et al. ${ }^{8}$ show a strong match between the SAED patterns from synthetic and biogenic ACC and calculated patterns for random packing of $\sim 1$-nm-sized calcite crystals. Similarly, we compare the powder XRD patterns for the F. septica HACC with the simulated scattering profiles for $~ 1$-nm-sized particles of anhydrous and hydrated $\mathrm{CaCO}_{3}$ polymorphs (Fig. 7, S20). Only the simulated pattern for monohydrocalcite shows four oscillations that match the $0.46,0.2866,0.204$, and $0.119 \mathrm{~nm}$ maxima for the $F$. septica HACC powder XRD patterns. The simulated pattern for monohydrocalcite further shows a weak oscillation near $0.1467 \mathrm{~nm}$ which, if present in the experimental pattern, is obscured by the tail of the intense $0.288 \mathrm{~nm}$ peak. However, the $0.2866 \mathrm{~nm}$ peak in the experimental pattern is considerably more intense than the corresponding peak in the simulated pattern for monohydrocalcite. The intensity of this peak can be simulated by assuming an HACC structure with both monohydrocalcite and calcite like nano-structural ordering (Fig. 7). The main maximum for the $\mathrm{HACC}$ at $0.2866 \mathrm{~nm}$ is at a higher d-spacing than that predicted by the simulations. A similar situation was shown between the calculated patterns for calcite and biogenic calcite, which Rez et al. ${ }^{8}$ attributed to the contraction of the nanocrystals relative to the bulk calcite. The simulations lend support to a structure composed of $\sim 1$-nm-sized diffracting domains, as the simulated patterns change dramatically 
just by doubling the particle size, with sharpening of the maxima and appearance of new peaks that are not present in the experimental patterns (Fig. S21).

\section{Conclusions}

The powder XRD, electron diffraction, IR data, and lack of optical birefringence are consistent with the $F$. septica HACC spheres as an amorphous material with sub-nanometer-sized diffracting domains. The XRD simulations are consistent with an HACC that possesses short-range structure with both monohydrocalcite- and calcite-like nano-structural properties, possibly reflecting a range of coordination environments from six to eight $\mathrm{O}$ around the $\mathrm{Ca}$. The EGA data are consistent with the breakdown of an organic framework to the DACC starting near $240^{\circ} \mathrm{C}$, culminating with a maximum in several EGA signals just prior to the first DSC exotherm, with partial crystallization. Together, the powder XRD, EGA, and elemental data suggest a structure dominated by 1-nm-sized monohydrocalcite- calcite-like units separated by organic material. Further, the $\sim 2-n m$-sized spacings present in the HACC XRD patterns suggest ordering at this scale that is disrupted as the mobile water is released. Previous work on ACC suggests that crystallization occurs from an intermediate anhydrous ACC. However, the slime mold DACC is not strictly anhydrous as $\sim 3 \mathrm{wt} \%$ water is released after the loss of the loosely bound water and before the first crystallization exotherm. This water loss is supported by the IR spectra that still show strong broad $\mathrm{H}_{2} \mathrm{O}$ FTIR absorption bands after heating to $208^{\circ} \mathrm{C}$.

The transformation and crystallization of the F. septica HACC by laboratory heating differs significantly from that observed in naturally weathered samples collected in the desert. Many examples of $F$. septica collected within days to months after their formation in the desert were vaterite rich, with one dominated by monohydrocalcite. These mineralogical differences suggest that the crystallization mechanism(s) via laboratory heating versus natural weathering are not the same. In the desert environment, the peridial ACC, which sits on the ground, will experience significant diurnal temperature and humidity variations ${ }^{51}$ : these variations could drive the reorganization of the ACC into different crystalline anhydrous or hydrous calcium carbonates. These data suggest that the transformation pathway is not necessarily predetermined by the initial HACC structure, but instead by environmental or laboratory conditions, a conclusion consistent previous findings ${ }^{17}$.

A major finding of our study is that the ACC precipitated by the slime mold $F$. septica is indefinitely stable under normal laboratory conditions. We propose that the intimate association of the organic matter with 1-nm-sized ACC units prevents its crystallization. The composition, structure, and thermal behavior of the HACC precipitated by $F$. septica collected over $8000 \mathrm{~km}$ apart, and in markedly different environments, suggests a common structure, as well as similar biochemical and biomineralization mechanisms for the HACC formation.

\section{Experimental Section}


Field observations. Fuligo septica is a cosmopolitan species ${ }^{37}$. Specimens collected in southern Arizona are commonly found after summer rains. The author observed specimens from the arid parts of southwestern Arizona to the more mesic mountain regions in the eastern part of the state. It is locally abundant, for example 103 aethalia were counted in a 15 x $5 \mathrm{~m}$ area $\left(33^{\circ} 16^{\prime} 33.14^{\prime \prime} \mathrm{N}, 111^{\circ} 9^{\prime} 57.25^{\prime \prime} \mathrm{W}\right.$, August 2018) under mesquite trees. Several hundred aethalia were found amongst perennial bushes and trees along a $1 \mathrm{~km}$ stretch of a dry wash $\left(33^{\circ} 1^{\prime} 58.15^{\prime \prime} \mathrm{N}, 112^{\circ} 14^{\prime} 35.99 " \mathrm{~W}\right.$, July 2017) southwest of Phoenix. The plasmodium emerges from the damp ground during the relative cool of the night and moves to an exposed position where it forms an aethalium. By morning, the aethalium is fully formed. The aethalia are typically pulvinate, 3 to $15 \mathrm{~cm}$ in diameter, and $2 \mathrm{~cm}$ thick. A cross section of the aethalium shows a dome-shaped peridium of white, soft, chalky material coating the spore mass (Fig. S1). The peridium and spore mass sit on the hypothallus. The peridium from eight separate aethalia of $F$. septica were collected during June 2018 in Highgate Woods, London ( $\left.51^{\circ} 35^{\prime} 0.38^{\prime \prime} \mathrm{N}, 0^{\circ} 8^{\prime} 59.42 \mathrm{~W}\right)$. The aethalia are pulvinate, bright canary yellow, with the largest to $7 \mathrm{~cm}$. The cortex is up to $3 \mathrm{~mm}$ thick and separated easily from the spore mass. The aethalia were all whole and undisturbed and it is estimated that they were collected within a few days of having formed. The Arizona and UK specimens studied here match the description for $F$. septica in ${ }^{37}$.

Separation of the ACC. The peridium from the Arizona (FSW) aethalia was easiest to collect from the stillmoist samples soon after collecting in the early morning. The white but damp peridium has a consistency of whipped cream cheese, which is easy to collect with a small spatula from the edge of aethalia. In this way, up to $200 \mathrm{mg}$ of pure, dried ACC could be separated from a single aethalia. The peridium can also be collected from the dry aethalia, although care is needed so as to not incorporate the underlying spores in the sample. In contrast, the peridium from the UK (FSY) samples separated easily from the spore mass as porous yellow chunks up to $1 \mathrm{~cm}$ across (Fig. S2).

Powder X-ray diffraction and simulations. Powder XRD patterns were acquired with a Rigaku MiniFlex 600 diffractometer. This diffractometer is operated with $\mathrm{Cu} K a$ radiation and is equipped with a postdiffraction graphite monochromator and automatic divergence slit system. Data was typically acquired in step scan mode at $0.02^{\circ}$ steps, and 30 to $60 \mathrm{~s} /$ step. Samples, typically weighing $\sim 10 \mathrm{mg}$, were mixed with a small drop of methanol forming a slurry. The resulting slurry was pipetted and spread into a thin, smooth film on a low-background, single-crystal, quartz plate. This slurry was dried rapidly ( $5 \mathrm{~s})$ under blowing warm air forming a thin film. In order to demonstrate that the methanol treatment did not affect the shape of the XRD profile, a sample was run as a dry powder sprinkled onto the quartz plate. The XRD pattern from the dry powder pattern and the thin film formed from the slurry were identical, showing that the methanol does not affect the slime mold HACC structure. Samples, weighing $~ 40 \mathrm{mg}$ each, were heated at $150^{\circ}, 300^{\circ}, 350^{\circ}$, and $500^{\circ} \mathrm{C}$ in air for $1 / 2 \mathrm{hr}$, and two samples of $\sim 20 \mathrm{mg}$ were heated at 365 and $446^{\circ} \mathrm{C}$ under flowing $\mathrm{He}$ for $1 / 2 \mathrm{hr}$. The specific heating temperatures were guided by the dominant changes observed in the TG-DSC data. The heated samples were deposited onto the quartz plate and the XRD pattern initially acquired rapidly $(1 / 2 \mathrm{hr})$ and then over an extended time period ( $20 \mathrm{hrs})$ to ensure that 
initially heated material remained stable. Samples were also periodically rerun over the course of months to two years to check for changes in the overall shape of the diffraction patterns.

Simulated patterns were calculated with the CrystalDiffract software by CrystalMaker Software Ltd. Patterns were calculated assuming Gaussian profiles, particle sizes were varied as shown in the figures and Iso strain was set to $0 \%$. Ideal lattice parameters were used for the simulations and site occupancies were set at $100 \%$.

TG-DTA/DSC. Thermal measurements were performed on a Setaram LabsysEvo (Lyon, France) TGDTA/DSC system, in flowing (60 mL/min) purging gas atmosphere [99.9999\% purity He /DTA/, 99.999\% purity $\mathrm{Ar} / \mathrm{DSC} /$ and $99.999 \%$ purity synthetic air $\left(20 \% \mathrm{O}_{2}\right.$ in $\left.\mathrm{N}_{2}\right)$ /DSC/ atmospheres]. The sample was weighed into a $100 \mu \mathrm{L} \mathrm{Al}_{2} \mathrm{O}_{3}$ crucible (the reference crucible was empty) and heated from $25^{\circ} \mathrm{C}$ to $1000^{\circ} \mathrm{C}$ with a heating rate of $10^{\circ} \mathrm{C} / \mathrm{min}$. Two measurements were done in one type of gas, one with a smaller amount of mass $(\sim 10 \mathrm{mg})$ and another one with a larger sample mass $(\sim 35 \mathrm{mg})$ in order to enhance the effects on the heat flow signal. The obtained data was baseline corrected and further processed with the thermoanalyzer's processing software (Calisto Processing, ver. 2.092). The thermal analyzer (both the temperature scale and calorimetric sensitivity) was calibrated by a multipoint calibration method, in which seven different certified reference materials (CRM's) were used to cover the thermal analyzer's entire operating temperature range.

TG-DSC-MSEGA. Thermal measurements were performed on a Setaram LabsysEvo (Lyon, France) TGDSC system, in flowing (90 mL/min) helium gas (99.9999\% purity) atmosphere. The sample was weighed directly into a $100 \mu \mathrm{L} \mathrm{Al}_{2} \mathrm{O}_{3}$ crucible (the reference cell was empty) and was heated from $25^{\circ} \mathrm{C}$ to $1000^{\circ} \mathrm{C}$ with a heating rate of $20^{\circ} \mathrm{C} / \mathrm{min}$. The obtained data was baseline corrected and further processed with the thermoanalyzer's processing software (Calisto Processing, ver. 2.092). The thermal analyzer (both the temperature scale and calorimetric sensitivity) was calibrated by a multipoint calibration method, in which seven different certified reference materials (CRM's) were used to cover the thermal analyzer's entire operating temperature range. In parallel with the thermal measurements, the analysis of evolved gases/volatiles was performed on a Pfeiffer Vacuum Omni Star ${ }^{\mathrm{rM}}$ mass spectrometric evolved gas analysis system (MS-EGA), which was connected to the above-mentioned thermal analyzer. The gas splitter was thermostated to $230^{\circ} \mathrm{C}$, while the transfer line to the mass spectrometer was thermostated to $220^{\circ} \mathrm{C}$. The temperature of the mass spectrometer gas inlet was programmed to $120^{\circ} \mathrm{C}$. The measurements were done in SEM Bargraph Cycles acquisition mode, where the $\mathrm{m} / \mathrm{z}$ interval of 11-130 was continuously scanned with a speed of $50 \mathrm{~ms} / \mathrm{amu}$. The spectrometer was operated in electron impact mode. The amount of "free" water was calculated by comparing the corresponding areas between room temperature and $200^{\circ} \mathrm{C}$ from two standard calibration materials (calcium oxalate monohydrate and potassium bicarbonate) adapted from the work of ${ }^{52}$.

FTIR spectroscopy. FTIR measurements were recorded on a Jasco FT/IR-4600 (Japan) system, equipped with a Jasco ATR Pro One single reflection diamond ATR (attenuated total reflection) accessory (incident angle $45^{\circ}$ ), and a mid-range MCT (Mercury-Cadmium-Telluride) detector. A spectral resolution of $4 \mathrm{~cm}^{-1}$ 
and co-addition of 128 individual spectra were applied. Prior to the evaluation, an ATR correction (Jasco Spectra Manager version 2, Spectra analysis module version 2.15.11) was performed on the raw spectra.

Scanning and transmission electron microscopy. Dry precipitates of the Fuligo septica HACC were gold coated and imaged with a ZEISS EVO 40 scanning electron microscope operated at $5 \mathrm{keV}$. TEM data were acquired with a $200 \mathrm{keV}$ Talos Thermo Scientific transmission electron microscope. Grains of the pristine material and samples heated at $208^{\circ}, 361^{\circ}$, and $500^{\circ} \mathrm{C}$ in an inert atmosphere for $1 / 2 \mathrm{hr}$ were crushed under ethanol and deposited onto copper grids covered by lacey carbon. We obtained BFTEM, and HAADF-STEM images as well as SAED patterns. The elemental composition of the grains was measured with a "Super-X" detector system having four silicon drift detectors built into the microscope column.

Proton-induced x-ray emission. Nondestructive elemental analysis of slime mold ACC was undertaken by proton-induced $x$-ray emission (PIXE) spectroscopy. Proton beams were accelerated at low energy (1.90 $\mathrm{MeV}$ ), with a $1.7 \mathrm{MeV}$ Tandetron tandem accelerator (Cockroft-Walton type manufactured by General Electric). The proton beam of $1 \times 1 \mathrm{~mm}$ crosses a 7.8-micron-thick kapton foil window before entering the sample chamber and striking the sample. The sample chamber is evacuated to low vacuum to avoid air signal and x-ray absorption. A Canberra $\mathrm{Si}(\mathrm{Li})$ detector (detector resolution at the $5.9 \mathrm{keV}$ line is $168.0 \mathrm{eV}$ ) is placed at $47^{\circ}$ from the normal of the sample surface, which is oriented at $45^{\circ}$ with respect to the incoming proton beam. No filters were used in front of the detector for the low-energy, light-element analyses. The proton current incident on the sample was adjusted to $\sim 0.5 \mathrm{nA}$.

PIXE was used to measure element concentrations of atomic number 11 (sodium) and greater. The spectra were acquired from areas $\sim 1 \times 1 \mathrm{~mm}$ on pressed 2-mm-diameter discs of ACC. Each spectrum was acquired for a total of 10,000 counts. The PIXE data were processed with the GUPIX software (www.physics.uoguelph.ca/PIXE, updated 2005). For standardization the instrumental constant $H$ (solid angle and correction factor) is determined using the GUPIX database (cross-sections, fluorescence and Coster-Kronig probabilities, stopping powers and attenuation coefficients) for the range of element in the NIST biological reference material Bovine Liver (SRM-1577) and whewellite. The bovine standard was run and $H$ determined prior to each ACC analysis. The C-H-N elemental data for the ACC (see below) were used to define the matrix for the GUPIX calculations.

CHN analysis. Bulk carbon, hydrogen, and nitrogen were determined using a Perking Elmer 2400 Elemental Analyzer in the Metals, Environmental and Terrestrial Analytical Laboratory at Arizona State University. Approximately $5 \mathrm{mg}$ of powder was used for each analysis. The samples were loaded into tin cups and flash heated to $1760^{\circ} \mathrm{C}$. The resulting gases were chemically scrubbed of the halogens and $\mathrm{S}$ and separated in a GC column. Detection is conducted by a thermal conductivity detector.

\section{Declarations}

Acknowledgements 
L.G. was funded in part by an ASU Investigator Incentive Award (IIA\# PG04789 CC0487). The research was also supported in part by the Ministry of Innovation and Technology of Hungary from the National Research, Development and Innovation Fund (projects FK141842, ANN141894 and NKFIH-872) and the Eötvös Loránd Research Network (NANOCARB project, SA-41/2021). We acknowledge the use of facilities within the Eyring Materials Center at Arizona State University supported in part by NNCI-ECCS-1542160. The authors are grateful to the following in the Eyring Materials Center for their assistance: PIXE (Barry Wilkens and Mark Mangus Jr), TG-DSC (Timothy Karcher and Xin Guo), and FTIR (Emmanuel Soignard), and to Cathy Kochert in the Metals, Environmental and Terrestrial Analytical Laboratory (METALS) at Arizona State University for help in measuring the $\mathrm{CHN}$ data. We are grateful to the staff and for the use of the Nanolab facility in the University of Pannonia.

\section{Author contributions}

L.G initiated the project. L.T. and L.G. measured the thermal and FTIR data. P.N. measured the TEM and SEM data. L.G acquired the XRD data. L.G. took the lead on the manuscript writing. All authors contributed substantially to all aspects of the data analysis and manuscript writing. All authors approved the manuscript.

\section{Competing interests}

The authors declare no competing interests.

\section{References}

1. Gebauer, D. et al. Proto-calcite and proto-vaterite in amorphous calcium carbonates. Angew. Chem. Int. Ed, 49, 8889-8891 (2010).

2. Goodwin, A. L. et al. Nanoporous structure and medium-range order in synthetic amorphous calcium carbonate. Chemistry of Materials, 22, 3197-3205 (2010).

3. Günther, C., Becker, A., Wolf, G. \& Epple, M. In vitro synthesis and structural characterization of amorphous calcium carbonate. Zeitschrift für anorganische und allgemeine Chemie, 631, 28302835 (2005).

4. Levi-Kalisman, Y., Raz, S., Weiner, S., Addadi, L. \& Sagi, I. X-Ray absorption spectroscopy studies on the structure of a biogenic "amorphous" calcium carbonate phase.Journal of the Chemical Society, Dalton Transactions,3977-3982(2000)

5. Michel, F. M. et al. Structural characteristics of synthetic amorphous calcium carbonate. Chemistry of Materials, 20, 4720-4728 (2008).

6. Politi, Y. et al. Transformation mechanism of amorphous calcium carbonate into calcite in the sea urchin larval spicule. Proceedings of the National Academy of Sciences 105, 17362-17366(2008)

7. Radha, A., Forbes, T. Z., Killian, C. E., Gilbert, P. \& Navrotsky, A. Transformation and crystallization energetics of synthetic and biogenic amorphous calcium carbonate. Proceedings of the National 
Academy of Sciences 107, 16438-16443 (2010)

8. Rez, P., Sinha, S. \& Gal, A. Nanocrystallite model for amorphous calcium carbonate. Journal of Applied Crystallography, 47, 1651-1657 (2014).

9. Sun, S., Chevrier, D. M., Zhang, P., Gebauer, D. \& Cölfen, H. Distinct Short-Range Order Is Inherent to Small Amorphous Calcium Carbonate Clusters (< 2 nm). Angew. Chem. Int. Ed, 55, 12206-12209 (2016).

10. Shen, Q. et al. Properties of amorphous calcium carbonate and the template action of vaterite spheres. The Journal of Physical Chemistry B, 110, 2994-3000 (2006).

11. Lee, H. S., Ha, T. H. \& Kim, K. Fabrication of unusually stable amorphous calcium carbonate in an ethanol medium. Materials Chemistry and Physics, 93, 376-382 (2005).

12. Rodriguez-Blanco, J., Shaw, S. \& Benning, L. G. How to make 'stable'ACC: protocol and preliminary structural characterization. Mineral. Mag, 72, 283-286 (2008).

13. Aizenberg, J., Addadi, L., Weiner, S. \& Lambert, G. Stabilization of amorphous calcium carbonate by specialized macromolecules in biological and synthetic precipitates. Adv. Mater, 8, 222-226 (1996).

14. Aizenberg, J., Lambert, G., Weiner, S. \& Addadi, L. Factors involved in the formation of amorphous and crystalline calcium carbonate: a study of an ascidian skeleton. Journal of the American Chemical Society, 124, 32-39 (2002).

15. Raz, S., Hamilton, P. C., Wilt, F. H., Weiner, S. \& Addadi, L. The transient phase of amorphous calcium carbonate in sea urchin larval spicules: the involvement of proteins and magnesium ions in its formation and stabilization. Adv. Funct. Mater, 13, 480-486 (2003).

16. Schmidt, M. P., Ilott, A. J., Phillips, B. L. \& Reeder, R. J. Structural changes upon dehydration of amorphous calcium carbonate. Crystal growth \& design, 14, 938-951 (2014).

17. Konrad, F., Gallien, F., Gerard, D. E. \& Dietzel, M. Transformation of amorphous calcium carbonate in air. Crystal growth \& design, 16, 6310-6317 (2016).

18. Bentov, S., Weil, S., Glazer, L., Sagi, A. \& Berman, A. Stabilization of amorphous calcium carbonate by phosphate rich organic matrix proteins and by single phosphoamino acids. Journal of structural biology, 171, 207-215 (2010).

19. Enyedi, N. T. et al. Cave bacteria-induced amorphous calcium carbonate formation. Scientific reports, $10,1-12$ (2020).

20. Gago-Duport, L., Briones, M., Rodríguez, J. \& Covelo, B. Amorphous calcium carbonate biomineralization in the earthworm's calciferous gland: pathways to the formation of crystalline phases. Journal of structural biology, 162, 422-435 (2008).

21. Hodson, M. E. et al. Biomineralisation by earthworms-an investigation into the stability and distribution of amorphous calcium carbonate. Geochemical transactions, 16, 1-16 (2015).

22. Levi-Kalisman, Y., Raz, S., Weiner, S., Addadi, L. \& Sagi, I. Structural differences between biogenic amorphous calcium carbonate phases using X-ray absorption spectroscopy. Adv. Funct. Mater, 12, 43-48 (2002). 
23. Addadi, L., Raz, S. \& Weiner, S. Taking advantage of disorder: amorphous calcium carbonate and its roles in biomineralization. Adv. Mater, 15, 959-970 (2003).

24. Benzerara, K. et al. The gammaproteobacterium Achromatium forms intracellular amorphous calcium carbonate and not (crystalline) calcite. Geobiology, 19, 199-213 (2021).

25. Rodríguez-Navarro, A. B., Marie, P., Nys, Y., Hincke, M. T. \& Gautron, J. Amorphous calcium carbonate controls avian eggshell mineralization: a new paradigm for understanding rapid eggshell calcification. Journal of structural biology, 190, 291-303 (2015).

26. Setoguchi, H., Okazaki, M. \& Suga, S. in Origin, evolution, and modern aspects of biomineralization in plants and animals409-418(Springer, 1989).

27. Bechtel, D. \& Horner, H. Calcium excretion and deposition during sporogenesis in Physarella oblonga. Calcified tissue research, 18, 195-213 (1975).

28. Chapman, C. P., Nelson, R. K. \& Orlowski, M. Peridium of the acellular slime moldFuligo septica: Structure and composition. Exp. Mycol, 6, 195-199 (1982).

29. Lado, C. \& Eliasson, U. Taxonomy and systematics: current knowledge and approaches on the taxonomic treatment of Myxomycetes.Myxomycetes,205-251(2017)

30. Schoknecht, J. D. SEM and X-ray microanalysis of calcareous deposits in myxomycete fructifications. Transactions of the American Microscopical Society,216-223(1975)

31. Schoknecht, J. D. \& Keller, H. W. in Origin, Evolution, and modern aspects of biomineralization in plants and animals455-488(Springer, 1989).

32. Keller, H. W., Everhart, S. E. \& Kilgore, C. M. in Myxomycetes 1-45 (Elsevier, 2022)

33. Keller, H. W., O'Kennon, B. \& Gunn, G. in Fun. 6-11 (Fun)

34. Nelson, R. K. \& Orlowski, M. Hypothallus of the acellular slime mold Fuligo septica: Structure and composition. FEMS Microbiology Letters, 18, 83-87 (1983).

35. Yajima, Y., Hoshino, T., Kondo, N. \& Chang, Y. C. Fruiting body formation of the nivicolous myxomycete Badhamia alpina in moist chamber culture. Mycoscience, 59, 268-276 (2018).

36. Zhang, J., Liu, L., Fiore-Donno, A. M. \& Xu, T. Ultrastructural characters of a Physarum melleum on living leaves of Dendrobium candidum in China. Journal of Zhejiang University SCIENCE B, 8, 896899 (2007).

37. Martin, G. W. \& Alexopoulos, C. J. The myxomycetes (University of lowa Press, 1969).

38. Casser, I., Steffan, B. \& Steglich, W. The chemistry of the plasmodial pigments of the slime mold Fuligo septica (Myxomycetes). Angewandte Chemie International Edition in English, 26, 586-587 (1987).

39. Setälä, A. \& Nuorteva, P. High metal contents found in Fulico septica (L.) wiggers and some other slime molds (Myxomycetes). Karstenia, 29, 37-44 (1989).

40. Zaghouani, M. \& Nay, B. 3-Acylated tetramic and tetronic acids as natural metal binders: myth or reality? Natural product reports, 33, 540-548 (2016). 
41. Koga, N. \& Yamane, Y. Thermal behaviors of amorphous calcium carbonates prepared in aqueous and ethanol media. Journal of Thermal Analysis and Calorimetry, 94, 379-387 (2008).

42. Sun, R. et al. Amorphous calcium carbonate constructed from nanoparticle aggregates with unprecedented surface area and mesoporosity. ACS applied materials \& interfaces, 10, 21556-21564 (2018).

43. Wang, Y. Y., Yao, Q. Z., Zhou, G. T. \& Fu, S. Q. Transformation of amorphous calcium carbonate into monohydrocalcite in aqueous solution: a biomimetic mineralization study. European Journal of Mineralogy, 27, 717-729 (2015).

44. Kimura, T. \& Koga, N. Monohydrocalcite in comparison with hydrated amorphous calcium carbonate: precipitation condition and thermal behavior. Crystal growth \& design, 11, 3877-3884 (2011).

45. Kimura, T. \& Koga, N. Thermal dehydration of monohydrocalcite: overall kinetics and physicogeometrical mechanisms. The Journal of Physical Chemistry A, 115, 10491-10501 (2011).

46. Koga, N., Nakagoe, Y. \& Tanaka, H. Crystallization of amorphous calcium carbonate. Thermochim. Acta, 318, 239-244 (1998).

47. Reeder, R. J. et al. Characterization of structure in biogenic amorphous calcium carbonate: Pair distribution function and nuclear magnetic resonance studies of lobster gastrolith. Crystal growth \& design, 13, 1905-1914 (2013).

48. Köll, P., Borchers, G. \& Metzger, J. Thermal degradation of chitin and cellulose. Journal of Analytical and Applied Pyrolysis, 19, 119-129 (1991).

49. Leontyev, D. V., Schnittler, M., Stephenson, S. L. \& Novozhilov, Y. K. Shchepin, O. N. Towards a phylogenetic classification of the Myxomycetes. Phytotaxa, 399, 209-238 (2019).

50. Ishii, Y., Nishiwaki, Y., Al-zubaidi, A. \& Kawasaki, S. Pore size determination in ordered mesoporous materials using powder X-ray diffraction. The Journal of Physical Chemistry C, 117, 18120-18130 (2013).

51. Garvie, L. A. J., Knauth, L. P., Bungartz, F., Klonowski, S. \& Nash, T. H. Life in extreme environments: survival strategy of the endolithic desert lichen Verrucaria rubrocincta., 95, 705-712 https://doi.org/doi:10.1007/s00114-008-0373-0 (2008).

52. Verchovsky, A. B., Anand, M., Barber, S. J., Sheridan, S. \& Morgan, G. H. A quantitative evolved gas analysis for extra-terrestrial samples. Planetary and Space Science, 181, 104830 (2020).

\section{Tables}


Table 1

Major element compositions (wt\%) for two FSW and one FSY HACC samples, and for monohydrocalcite. Additional compositional details are in Tables S1 and S2.

\begin{tabular}{|c|c|c|c|c|c|c|c|}
\hline & \multicolumn{7}{|c|}{ Major Element (wt\%) } \\
\hline & $\mathrm{Ca}_{\mathrm{p}}$ & $\mathrm{M}_{\text {tot-TG }}$ & $\mathrm{Mn}_{\mathrm{P}}$ & $\mathrm{O}_{\text {dif }}$ & C & $\mathrm{H}$ & $\mathbf{N}$ \\
\hline \multirow[t]{2}{*}{ FSW21 } & 30.5 & 31.9 & 0.12 & 53.375 & 12.49 & 2.505 & 1.01 \\
\hline & $(n=3)$ & & & & & & \\
\hline \multirow[t]{2}{*}{ FSW22 } & 32.4 & n.d. & 0.12 & 52.115 & 12.145 & 2.350 & 0.87 \\
\hline & $(n=3)$ & & & & & & \\
\hline \multirow[t]{2}{*}{$\mathrm{FSW}_{\mathrm{avg}}$} & 31.5 & - & 0.12 & 52.745 & 12.32 & 2.428 & 0.94 \\
\hline & $(31.5 \pm 1.5)$ & & & & & & \\
\hline \multirow[t]{2}{*}{ FSY1 } & 28.1 & 31.92 & 3.33 & 49.84 & 14.63 & 2.62 & 1.50 \\
\hline & $(n=2)$ & & $(n=2)$ & & & & \\
\hline $\begin{array}{l}\text { Monohydro- } \\
\text { calcite }\end{array}$ & 33.94 & - & - & 54.19 & 10.17 & 1.71 & - \\
\hline
\end{tabular}

$\mathrm{P}$ - PIXE. $\mathrm{M}_{\mathrm{tot}-\mathrm{TG}}$ - total metal wt\% determined by TG assuming that the product after heating to $1000^{\circ} \mathrm{C}$ is $(\mathrm{Ca}, \mathrm{Mn}) \mathrm{O}$ only. $\mathrm{O}_{\text {diff }}$ - oxygen determined by the difference of other measured elements. $\mathrm{C}, \mathrm{H}, \mathrm{N}$ by bulk $\mathrm{CHN}$ analysis. n.d. - not determined

Figures 


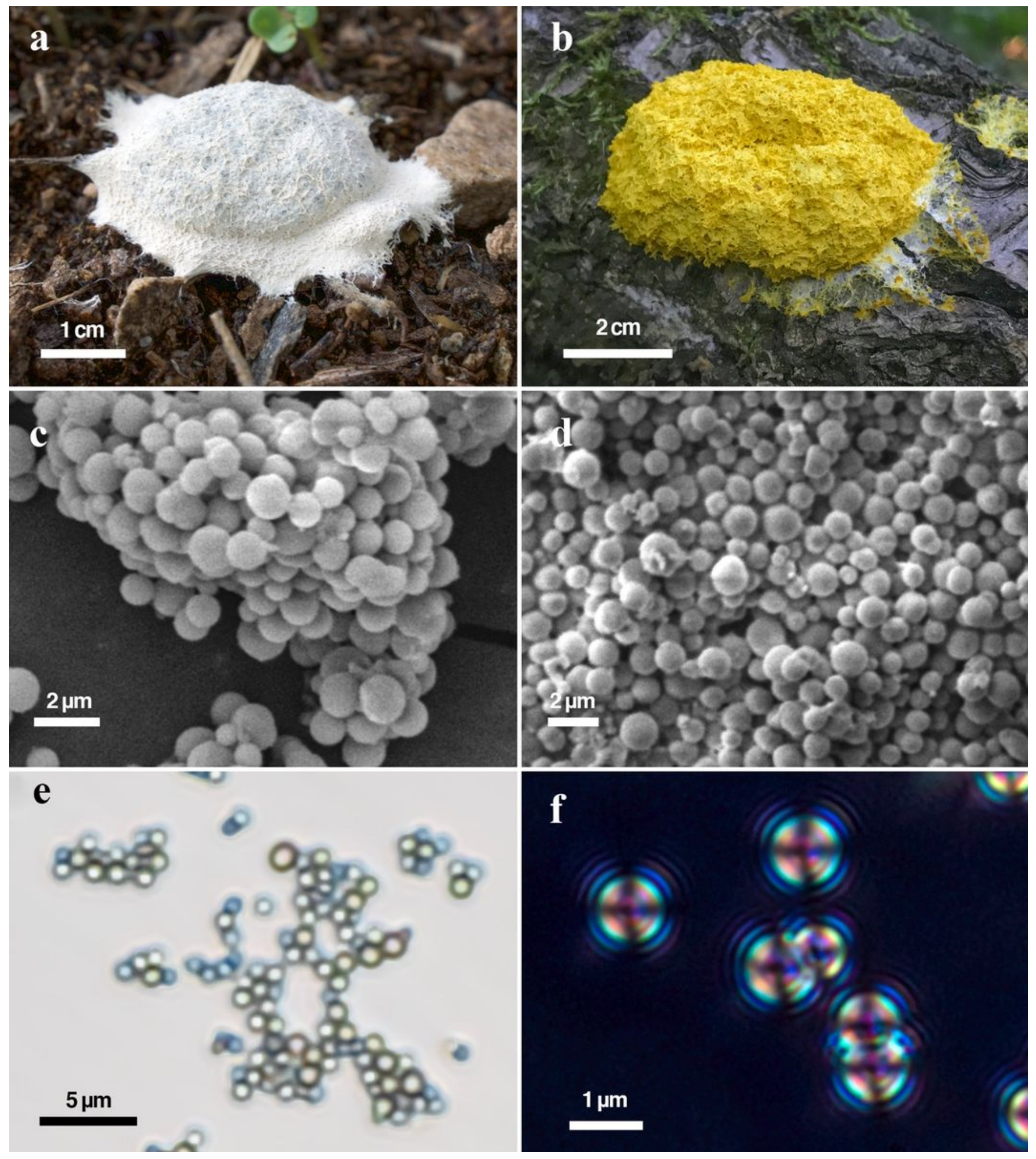

\section{Figure 1}

Photographs of Fuligo septica aethalia of (a) typical Arizona specimen (FSW), and (b) yellow specimen from the UK (FSY), and corresponding BSE SEM images of the peridium (c, d) showing the fundamental spherical morphology of the peridial HACC. (e) Optical transmitted light microscope image of a cluster of HACC spheres, and (f) crossed-polarized transmitted light optical image of the spheres. The spheres show dark isogyres and isochromatic rings characteristic of an amorphous material. 

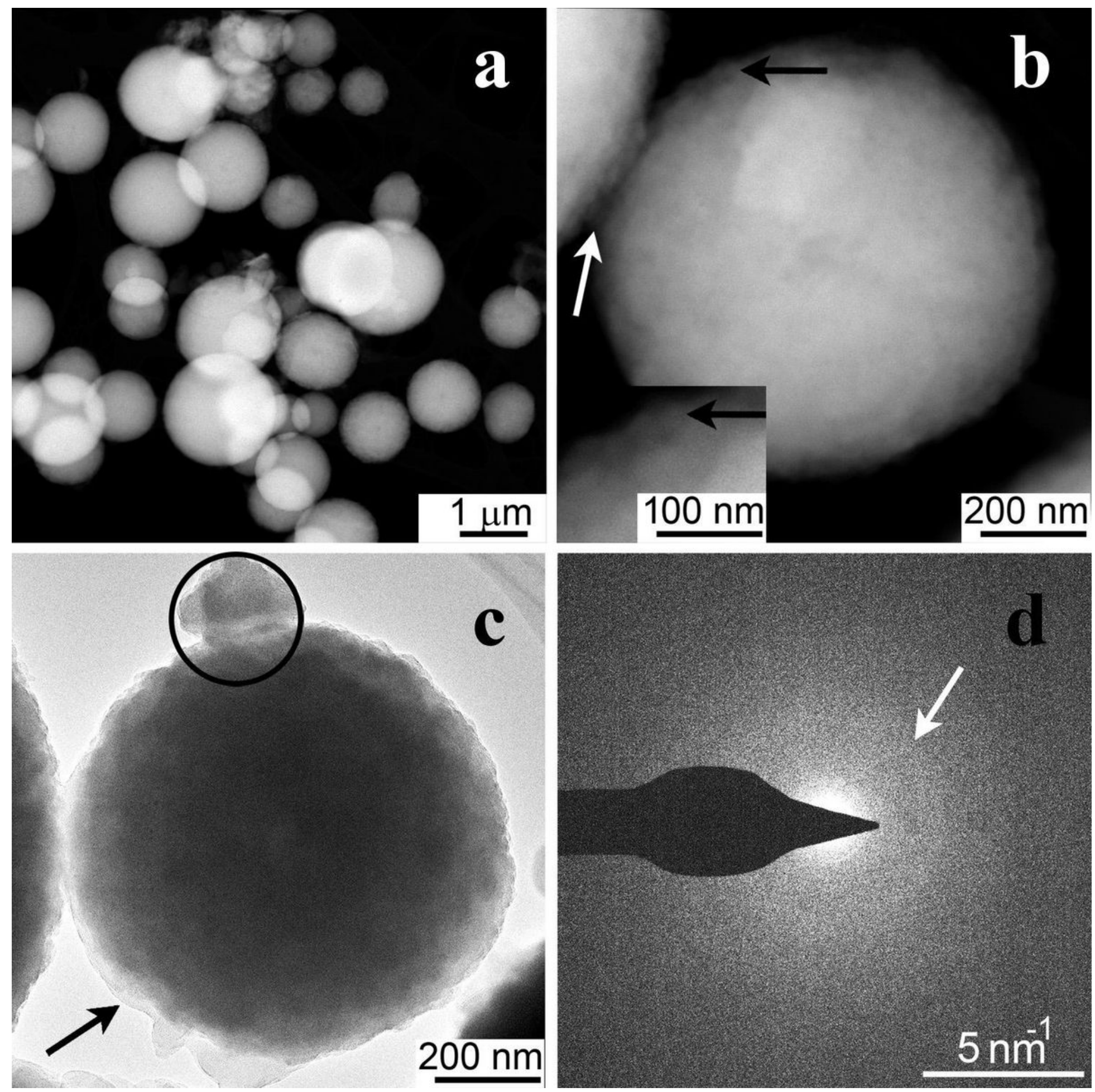

Figure 2

Morphology and structure of the FSY HACC precipitated by Fuligo septica. (a) Low-magnification HAADFSTEM image of the peridial HACC spheres. (b) HAADF-STEM and (c) BFTEM images of one sphere. Black arrow marks 30- 40-nm size quasi-spherical features. Imaged processed to more clearly reveal the internal clumping is shown in Fig. S3. (d) SAED pattern acquired from the circled area of (c). White arrow points to a diffuse diffraction ring with $\mathrm{d} \sim 0.29 \mathrm{~nm}$ spacings. 

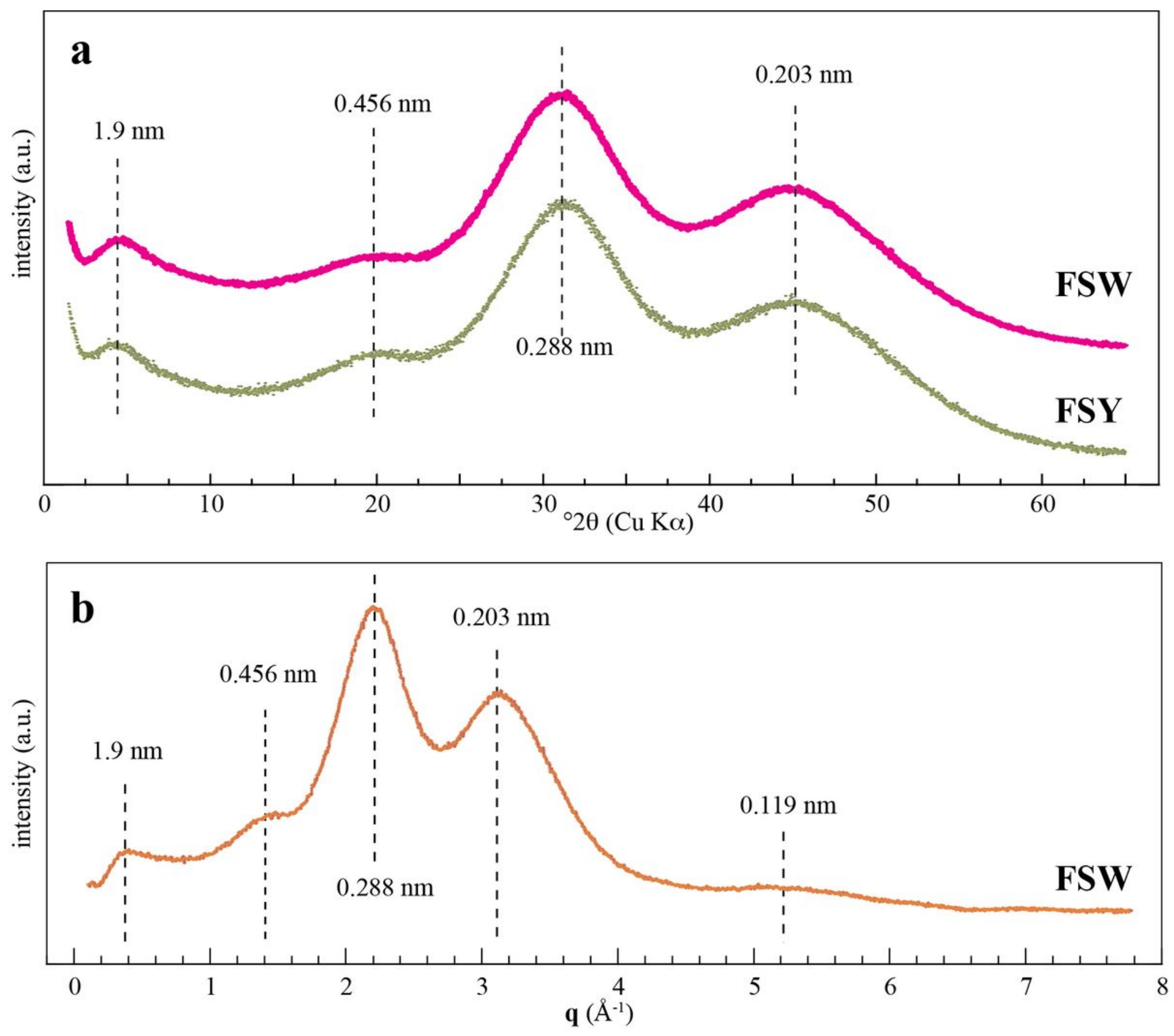

Figure 3

Powder x-ray diffraction patterns from representative HACC samples from the Arizona (FSW) and UK (FSY) Fuligo septica peridia. The FSY pattern is from the same aethalia shown in Figure 1b. (a) Raw powder x-ray diffraction patterns. (b) X-ray diffraction pattern from FSW after background subtraction and intensities plotted as a function of scattering vector $q(\AA-1)$. 

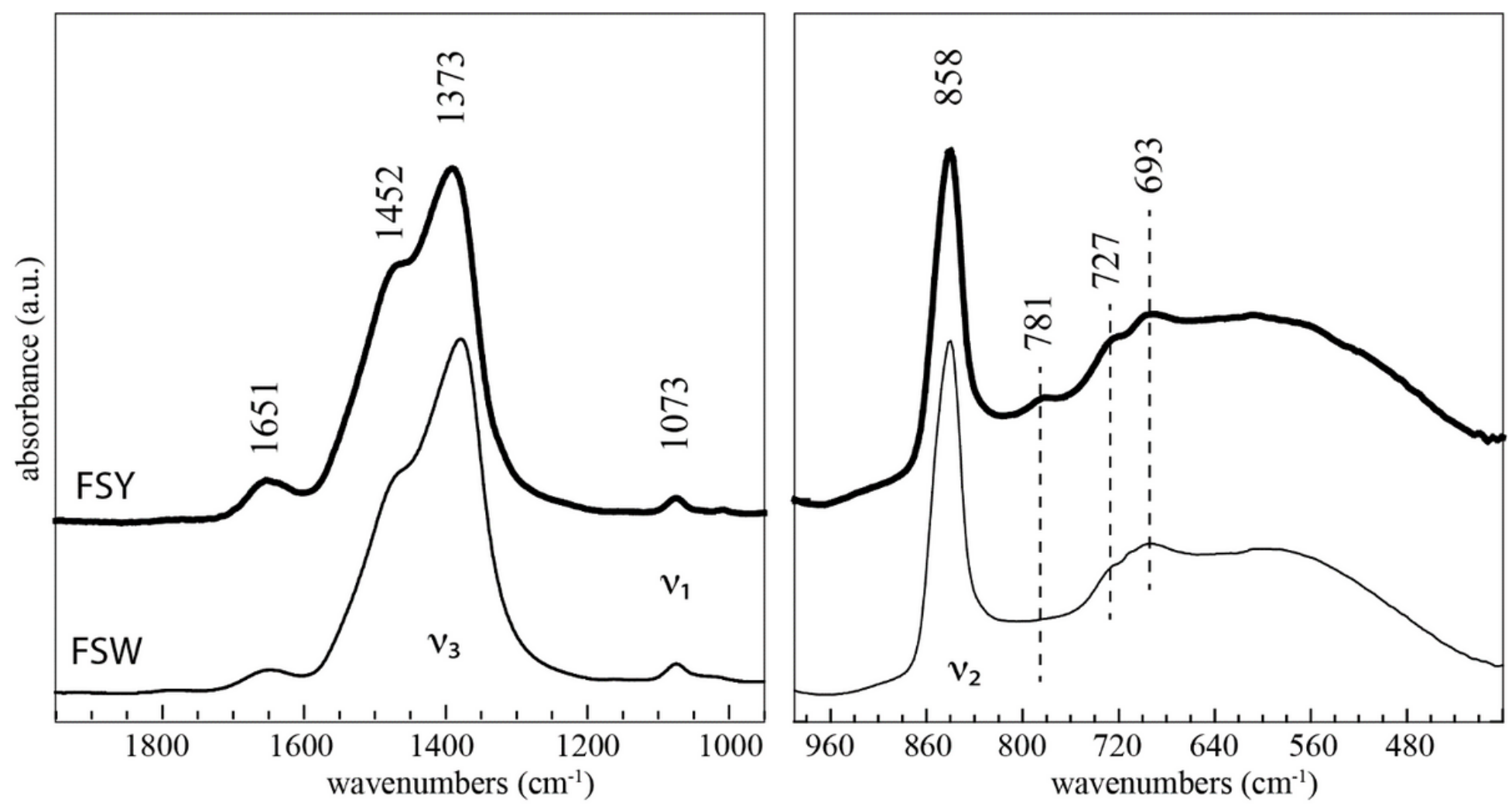

Figure 4

Selected regions of the IR spectra of FSY (sample FS1) and FSW (sample FSW4) HACC acquired at room temperature. Full spectra are shown in the supplementary information (Figs. S4, S16). 


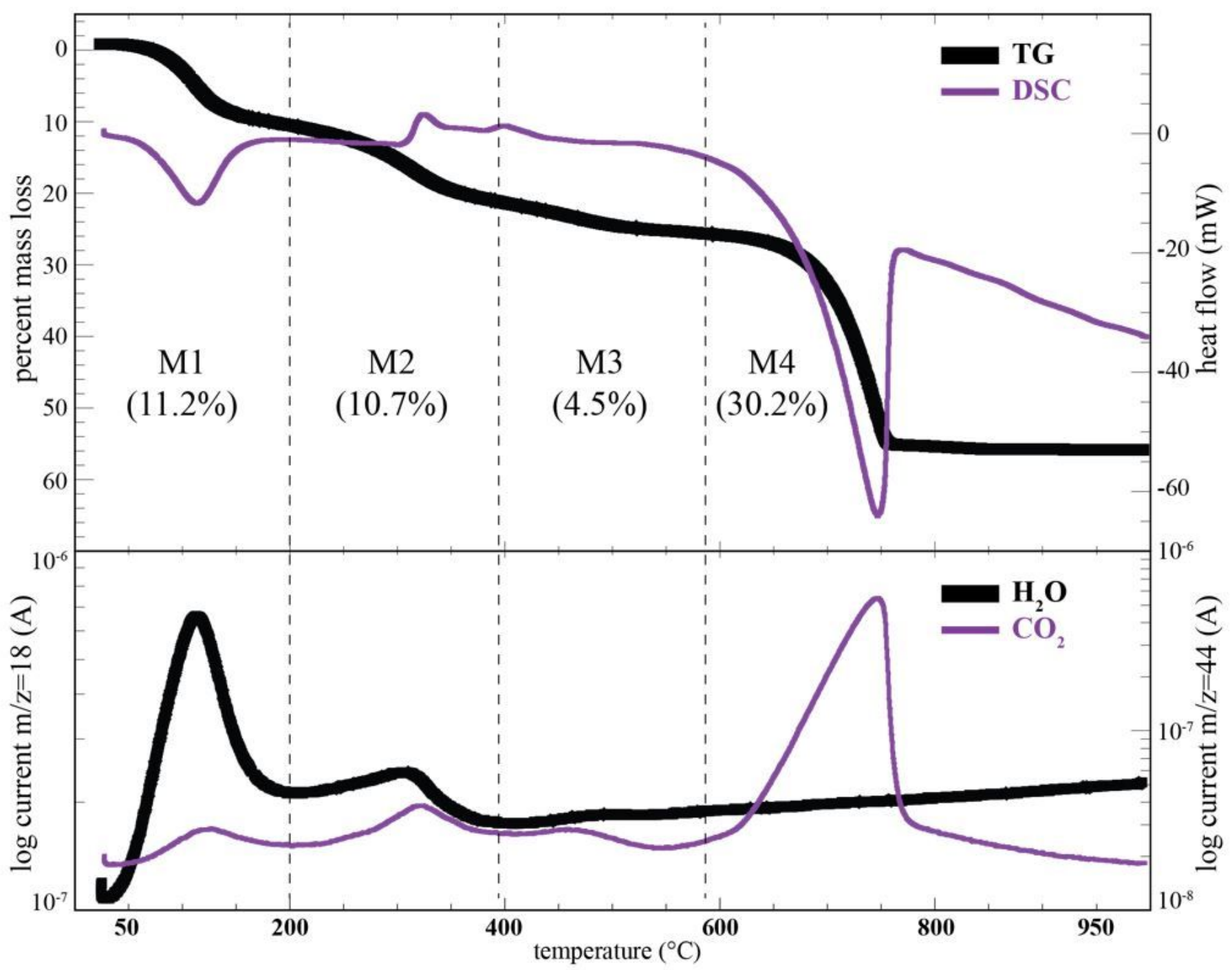

Figure 5

Thermal (TG and DSC) and EGA data for the FSY HACC. M1 to M4 refer to the four distinct mass-loss ranges discussed in the text, and the corresponding percent mass loss within each range in parentheses. The EGA data show the curves for $\mathrm{m} / \mathrm{z}=18(\mathrm{H} 2 \mathrm{O}+)$ and $\mathrm{m} / \mathrm{z}=44(12 \mathrm{CO} 2+)$. 


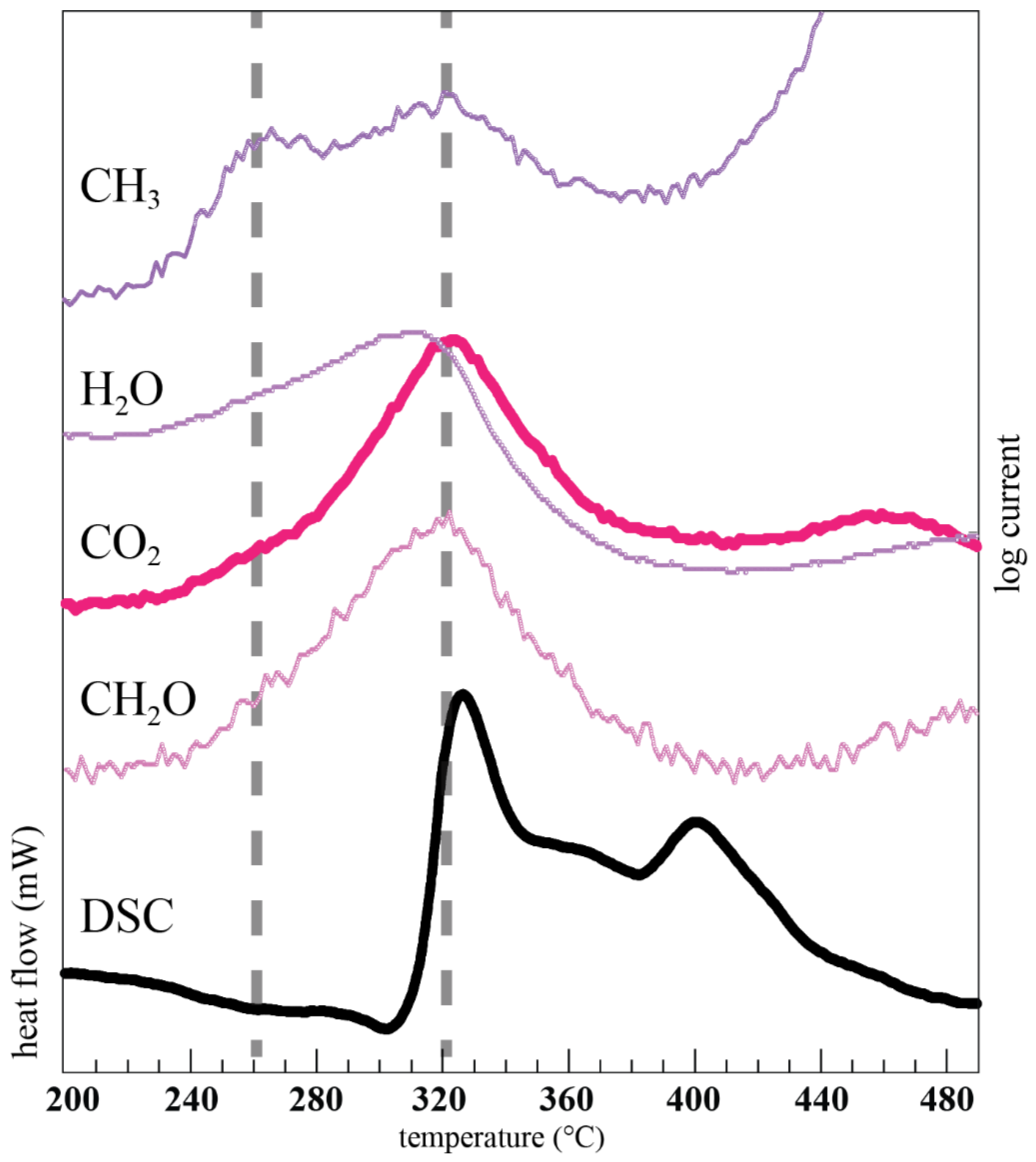

Figure 6

Comparison of the exothermic DSC region (in $\mathrm{mW}$ ) for the FSY sample run under $\mathrm{He}$ (bottom curve) compared with selected EGA profiles (ion current) corresponding to $\mathrm{CH} 2 \mathrm{O}+(\mathrm{m} / \mathrm{z}=30), 12 \mathrm{CO} 2+(\mathrm{m} / \mathrm{z}=44)$, $\mathrm{H} 2 \mathrm{O}+(\mathrm{m} / \mathrm{z}=18)$, and $\mathrm{CH} 3+(\mathrm{m} / \mathrm{z}=15)$. Additional gas assignments are listed in the figure caption for Figure S10. All profiles are scaled and shifted along the $y$-axis so as to show the correspondence between the peak maxima. The absolute EGA scales are shown in Figure S10. 


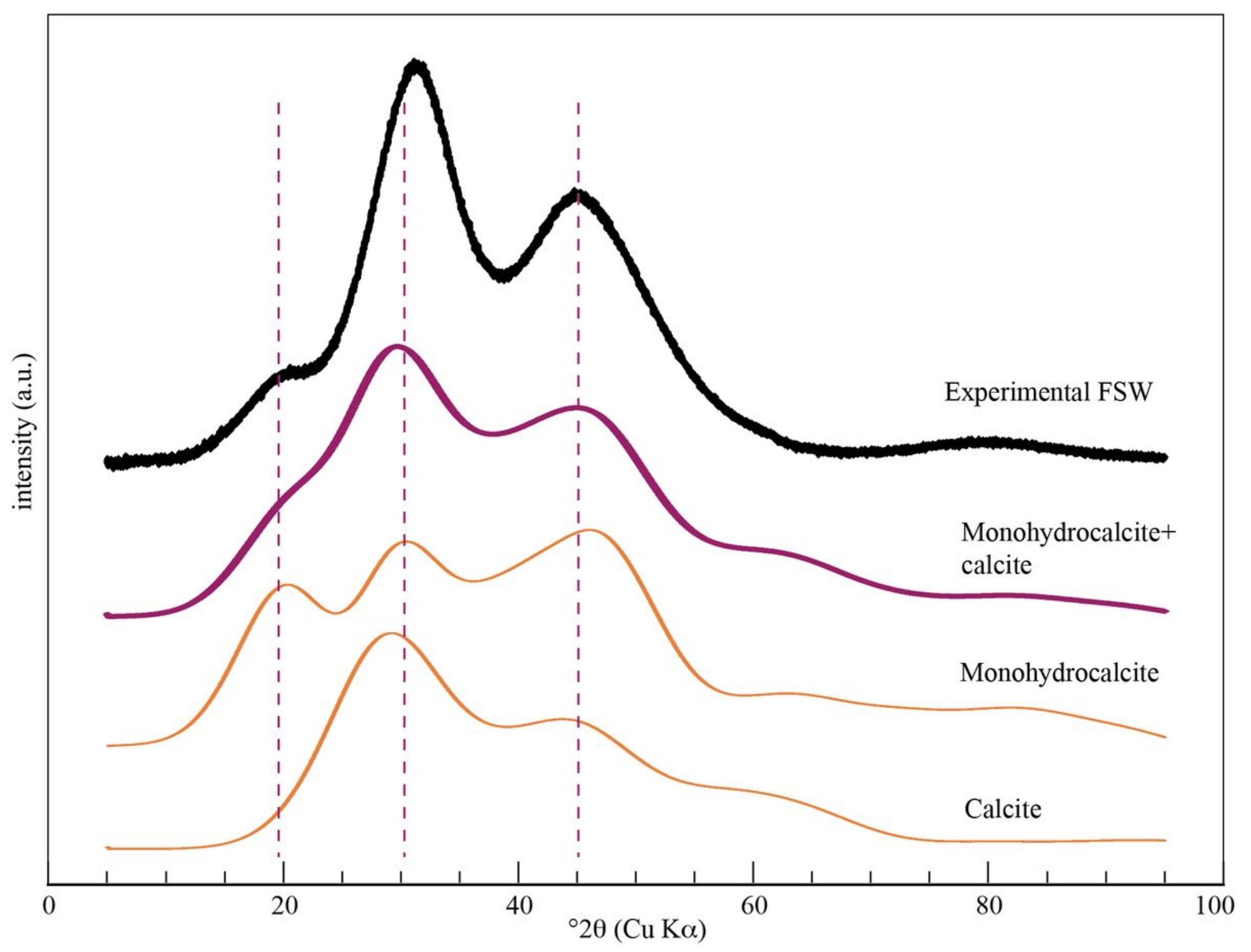

Figure 7

Comparison of the experimental XRD diffraction profile for the FSW HACC compared with simulated patterns for 0.8-nm calcite, 1-nm monohydrocalcite, and a linear sum of the two (Monohydrocalcite+calcite). The measured background below the experimental pattern has been subtracted as well as the contribution from the $1.9 \mathrm{~nm}$ peak.

\section{Supplementary Files}

This is a list of supplementary files associated with this preprint. Click to download.

- slimemoldpapersuppl.docx 